\title{
Defining essential elements and genetic interactions of the yeast Lsm2-8 ring and demonstration that essentiality of Lsm2-8 is bypassed via overexpression of U6 snRNA or the U6 snRNP subunit Prp24
}

\author{
ALLEN J. ROTH, ${ }^{1}$ STEWART SHUMAN, ${ }^{2}$ and BEATE SCHWER ${ }^{1}$ \\ ${ }^{1}$ Microbiology and Immunology Department, Weill Cornell Medical College, New York, New York 10065, USA \\ ${ }^{2}$ Molecular Biology Program, Sloan-Kettering Institute, New York, New York 10065, USA
}

\begin{abstract}
A seven-subunit Lsm2-8 protein ring assembles on the U-rich $3^{\prime}$ end of the U6 snRNA. A structure-guided mutational analysis of the Saccharomyces cerevisiae Lsm2-8 ring affords new insights to structure-function relations and genetic interactions of the Lsm subunits. Alanine scanning of 39 amino acids comprising the RNA-binding sites or intersubunit interfaces of Lsm2, Lsm3, Lsm4, Lsm5, and Lsm8 identified only one instance of lethality (Lsm3-R69A) and one severe growth defect (Lsm2-R63A), both involving amino acids that bind the $3^{\prime}$-terminal UUU trinucleotide. All other Ala mutations were benign with respect to vegetative growth. Tests of 235 pairwise combinations of benign Lsm mutants identified six instances of inter-Lsm synthetic lethality and 45 cases of nonlethal synthetic growth defects. Thus, Lsm2-8 ring function is buffered by a network of internal genetic redundancies. A salient finding was that otherwise lethal single-gene deletions $I s m 2 \Delta, I s m 3 \Delta, I s m 4 \Delta, I s m 5$, and $I s m 8 \Delta$ were rescued by overexpression of U6 snRNA from a high-copy plasmid. Moreover, U6 overexpression rescued myriad Ism $\Delta$ Ism $\Delta$ double-deletions and Ism $\Delta$ Ism $\Delta$ Ism $\Delta$ triple-deletions. We find that U6 overexpression also rescues a lethal deletion of the U6 snRNP protein subunit Prp24 and that Prp24 overexpression bypasses the essentiality of the U6-associated Lsm subunits. Our results indicate that abetting U6 snRNA is the only essential function of the yeast Lsm2-8 proteins.
\end{abstract}

Keywords: Lsm proteins; Prp24; U6 snRNA; mRNA splicing

\section{INTRODUCTION}

Seven paralogous Sm proteins and seven paralogous Lsm proteins assemble into hetero-heptameric rings that decorate sequences at or near the $3^{\prime}$ ends of the spliceosomal $U$ snRNAs. The Sm ring forms the core scaffold of the U1, $\mathrm{U} 2$, U4, and U5 small ribonuclear proteins (snRNPs). The uridine-rich Sm site of the snRNA threads through the central hole of the Sm ring so that individual RNA nucleobases are engaged sequentially ( $5^{\prime}$ to $\left.3^{\prime}\right)$ by the SmF, SmE, SmG, SmD3, SmB, SmD1, and SmD2 subunits (Kondo et al. 2015; Li et al. 2016). The subunit arrangement of the yeast U6-associated Lsm ring (as depicted in Fig. 1A) is Lsm6, Lsm5, Lsm7, Lsm4, Lsm8, Lsm2, Lsm3 (Zhou et al. 2014a). The crystal structure of the yeast Lsm ring in complex with a pentanucleotide RNA $5^{\prime}$-GUUUU, corresponding to the $3^{\prime}$-terminal sequence of U6 snRNA, revealed that the

\footnotetext{
Corresponding authors: bschwer@med.cornell.edu, s-shuman@ski.mskcc. org

Article is online at http://www.rnajournal.org/cgi/doi/10.1261/rna.066175. 118.
}

RNA does not thread through the central aperture of the Lsm ring, but is engaged on one side of the hole's circumference, via sequential $5^{\prime}$-to- $3^{\prime}$ contacts of the nucleotides to subunits Lsm4, Lsm8, Lsm2, and Lsm3 (Fig. 1A; Zhou et al. 2014a).

The conserved fold of the Sm and Lsm subunits comprises a 5 -strand antiparallel $\beta$ sheet, embellished in some cases by additional secondary structure elements and/or unstructured C-terminal extensions of varying length (Kambach et al. 1999; Wu et al. 2012; Zhou et al. 2014a; Kondo et al. 2015; Li et al. 2016). The stereotypic Sm and Lsm protein-RNA contacts are made by an amino acid triad, whereby the planar nucleobase is sandwiched by an arginine or lysine side chain from the $\beta 4-\beta 5$ loop (which makes a $\pi$-cation stack on the nucleobase) and a side chain from the $\beta 2-\beta 3$ loop (often

(C) 2018 Roth et al. This article is distributed exclusively by the RNA Society for the first 12 months after the full-issue publication date (see http:// rnajournal.cshlp.org/site/misc/terms.xhtml). After 12 months, it is available under a Creative Commons License (Attribution-NonCommercial 4.0 International), as described at http://creativecommons.org/licenses/by-nc/ $4.0 /$. 
A

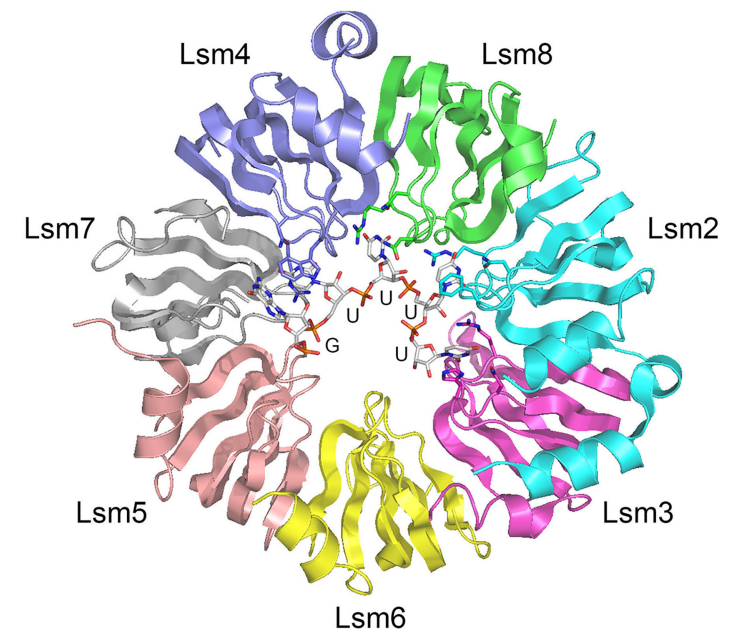

B

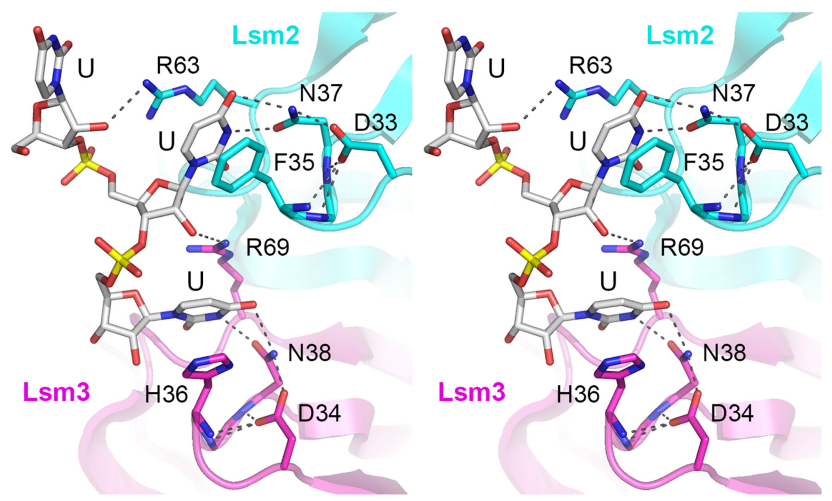

FIGURE 1. Topology and RNA interface of the Lsm2-8 ring. (A) Structure of the yeast Lsm2-8 ring in complex with $5^{\prime}$-GUUUU RNA (Zhou et al. 2014a, pdb 4M7A). The Lsm subunits are shown as cartoon traces and color-coded as indicated. The RNA is depicted as a stick model. (B) Stereo view (wall-eyed) of the RNA interface of the Lsm 2 and Lsm3 subunits, which contact the 3 -terminal UpUpU trinucleotide. The base-stacking and hydrogen-bonding interactions of the RNA-binding triad amino acids (Phe35, Asn37, and Arg63 in Lsm2; His36, Asn38, and Arg69 in Lsm3) are shown. The structural images were prepared in Pymol.

an aromatic group that forms a $\pi$ stack on the nucleobase), while an asparagine side chain of the $\beta 2-\beta 3$ loop makes hydrogen bonds to the nucleobase edge. These triad contacts are depicted for Lsm2 and Lsm3 in detail in Figure 1B.

We undertook recently to leverage the advances in snRNP structural biology to the genetics of budding yeast to elucidate the structure-function relationships and genetic interactions of the seven Sm ring subunits, each of which is essential for yeast viability. Our strategy was to use human U1 and U4 snRNP crystal structures (Kondo et al. 2015; Li et al. 2016) to guide mutagenesis in Saccharomyces cerevisiae. We performed an alanine scan of 54 conserved yeast equivalents of the amino acids of the human Sm subunits that either contact the snRNA, the neighboring subunits of the Sm ring, or non-Sm subunits of the U1 snRNP. Given the conservation from yeast to humans of the core Sm ring structure and the shared principle of RNA recognition via an amino acid triad present in each Sm subunit, one might have expected the Sm protein-RNA complex to be functionally acutely sensitive to perturbations of the protein-RNA interface and/or Sm-Sm subunit interface. This is clearly not the case in budding yeast, insofar as only two of 54 alanine mutations were lethal (Schwer and Shuman 2015; Schwer et al. 2016, 2017). Lethal single-alanine mutations were confined to the RNA-binding sites of SmD1 (Arg88) and SmD2 (Arg97), thus highlighting the unique importance of their $\pi$-cation interactions with the sixth and seventh nucleobases of the Sm RNA site, respectively. This conclusion was fortified by the finding that both arginines can be replaced functionally by lysine. Alanine mutation of SmF Arg74 caused a severe growth defect, which was reversed by lysine, signifying that the $\pi$ cation stack on the first nucleobase of the Sm RNA site is important too.

The remarkable tolerance of the seven yeast Sm proteins to mutations of the amino acids at their RNA interfaces or protein-protein interfaces suggested that the Sm ring system has built-in redundancy. To comprehensively address this issue, we conducted an "all-against-all" test of 406 different pairwise combinations of structure-guided mutations in any two of the Sm ring subunits, which unveiled a wide network of 137 intersubunit synthetic lethalities (Schwer and Shuman 2015; Schwer et al. 2016, 2017). A key conclusion was that five of seven intact RNA-binding sites in the Sm ring do not suffice for in vivo function.

Here we extend the structure-guided mutagenesis approach to the Lsm subunits of the yeast U6 snRNP, which consists of the 112-nucleotide (nt) U6 snRNA in complex with protein Prp24 and the Lsm2-8 heptameric ring (Montemayor et al. 2014; Zhou et al. 2014a; Didychuk et al. 2018). Lsm2, Lsm3, Lsm4, Lsm5, and Lsm8 are essential for yeast viability (Mayes et al. 1999). In contrast, $l s m 6 \Delta$ and $l s m 7 \Delta$ cells are viable, albeit defective for growth at high temperatures (Mayes et al. 1999; Salgado-Garrido et al. 1999). Deletion or transient depletion of any one of the yeast U6associated Lsm subunits leads to reduced steady-state levels of U6 snRNA, suggesting that the Lsm2-8 ring promotes U6 snRNA stability (Mayes et al. 1999; Salgado-Garrido et al. 1999). Lsm genetic analysis is complicated by the fact that six of the U6-associated Lsm subunits (Lsm2-7) are components of a distinct Lsm1-7 heptameric ring complex that functions in mRNA decapping and decay (Tharun et al. 2000). The structure of the yeast Lsm1-7 ring reveals that Lsm1 occupies the same position in the ring as does Lsm8 in the U6-associated complex (Sharif and Conti 2013; Zhou et al. 2014b). Otherwise, the topology of the Lsm1-7 ring (Lsm1-2-3-6-5-7-4) is shared with the Lsm28 ring (Lsm8-2-3-6-5-7-4).

As we report here, an extensive alanine scan focused on the RNA and protein-protein interfaces of Lsm2-3-4-5-8 identified only one amino acid as essential in vivo (Lsm3Arg69) and one where alanine elicits a severe growth defect 
(Lsm2-Arg63). These two arginines bind the $3^{\prime}$-terminal UUU trinucleotide of U6 snRNA (Fig. 1B). Tests of 235 pairwise combinations of otherwise benign mutations unveiled six cases of synthetic lethality and 45 instances of nonlethal synthetic growth defects. Thus, the U6-associated Lsm2-8 ring, like the Sm ring, has inherent functional redundancy. We show that each of the essential components of the Lsm2-8 ring, as well as the U6 snRNP subunit Prp24, can be rendered dispensable by overexpression of U6 snRNA. Moreover, the essential subunits of Lsm2-8 can be bypassed by overexpression of Prp24.

\section{RESULTS AND DISCUSSION}

\section{Structure-guided mutagenesis of the five essential yeast U6-associated Lsm subunits}

The amino acid sequences of the essential yeast Lsm2, Lsm3, Lsm4, Lsm5, and Lsm8 proteins are shown in Figure 2A along with their secondary structure elements, as seen in the crystal structure of the Lsm2-8 ring bound to RNA (pdb 4M7A). The 39 amino acids we targeted for alanine scanning and functional testing in vivo are shaded gold for residues comprising the canonical Sm/Lsm RNA-binding triad, green for a conserved aspartate that stabilizes the $\beta 2-\beta 3$ RNAbinding loop via hydrogen bonds to the loop main chain amides and the triad asparagine side-chain amide (Fig. 1B), and blue for amino acids at the interfaces with vicinal Lsm subunits. Because the RNAbinding triad residues of the yeast Lsm proteins had previously been subjected to alanine scanning and determination of mutational effects on the affinity of binding of the recombinant Lsm2-8 complex to an 8-mer oligoribonucleotide 5'-UUCGUUUU corresponding to the $3^{\prime}$ end of yeast U6 snRNA (Zhou et al. 2014a), we aimed to correlate, where possible, genetic and biochemical phenotypes. We also tested the in vivo effect of deleting the 92-amino acid C-terminal tail of Lsm4, an asparagine-rich segment (Fig. 2A) that was intentionally removed in preparing the recombinant Lsm2-8 complex used for crystallography (Zhou et al. 2014a).

The wild-type $L S M, L S M-A l a$, and LSM4-CA92 alleles were placed on CEN

\section{A}

\section{B}

HIS3 plasmids under the control of the respective native $L S M$ promoters and tested by plasmid shuffle for complementation of the corresponding lsm $\Delta \mathrm{p}$ [CEN URA3 LSM] strains. Thirty-seven of the LSM-Ala strains and the LSM4$C \triangle 92$ strain were viable after FOA selection and grew as well as wild-type $L S M$ cells on YPD agar at $18^{\circ} \mathrm{C}-37^{\circ} \mathrm{C}$ (see exemplary spot tests for growth of Lsm2 and Lsm3 mutants in Supplemental Fig. S1); these alleles are highlighted in LSM8 109 aa

\begin{tabular}{|c|c|c|c|c|}
\hline Lsm2 & Lsm3 & Lsm4 & Lsm5 & Lsm8 \\
\hline$E 24 A$ & $D 13 A$ & $K 20 A$ & $R 28 A$ & D31A \\
\hline D33A & Q31A & $E 23 A$ & $E 29 A$ & N33A \\
\hline F35A & $D 34 A$ & D33A & D38A & T34A \\
\hline N37A & $H 36 A$ & W35A & $F 40 A$ & N35A \\
\hline$R 63 A$ & N38A & N37A & $N 42 A$ & $R 57 A$ \\
\hline$R 63 K$ & $E 46 A$ & $E 45 A$ & $E 50 A$ & S59A \\
\hline$R 63 Q$ & $R 61 A$ & $R 72 A$ & $H 67 A$ & $E 60 A$ \\
\hline Y69A & R69A & $C \Delta 92$ & $S 74 A$ & \multirow[b]{3}{*}{ lethal } \\
\hline \multirow[t]{4}{*}{ Q83A } & $R 69 \mathrm{~K}$ & & & \\
\hline & $R 69 Q$ & & & \\
\hline & $S 77 A$ & & & sick \\
\hline & T78A & & & +++ \\
\hline
\end{tabular}

FIGURE 2. Structure guided mutagenesis of the five essential U6-associated Lsm subunits. (A) The primary structures of $S$. cerevisiae Lsm2, Lsm3, Lsm4, Lsm5, and Lsm8 are shown. The secondary structure elements (from the structure in Fig. 1A) are depicted above the amino acid sequences as magenta $\beta$ strands (arrows) and cyan $\alpha$ helices (cylinders). The amino acids subjected to alanine scanning mutagenesis are shaded in gold (RNA-binding triads), green (conserved Asp that stabilizes the $\beta 2-\beta 3$ RNA-binding loop), or blue (intersubunit interface). The $\mathrm{C}$ terminus of the Lsm4-C $\Delta 92$ truncation mutant is indicated by the reverse arrowhead. $(B)$ The wild-type and mutated $L S M$ alleles were tested for $1 \mathrm{~s} m \Delta$ complementation by plasmid shuffle. Lethal alleles that failed to support growth on FOA are highlighted in red boxes. Viable LSM-Ala and $L S M 4-C \Delta 92$ strains were spot-tested for growth on YPD agar at $18^{\circ} \mathrm{C}-37^{\circ} \mathrm{C}$. Those that grew as well as wild-type $L S M$ cells $(+++)$ are highlighted in gray boxes. Strains that were very sick (tiny colonies at all temperatures) are highlighted in yellow boxes. 
gray boxes in Figure 2B. The LSM3-R69A allele was uniquely lethal, i.e., no FOA-resistant colonies were obtained after $8 \mathrm{~d}$ of incubation at $20^{\circ} \mathrm{C}, 30^{\circ} \mathrm{C}$, or $37^{\circ} \mathrm{C}$. To examine structureactivity relations at this essential RNA-binding arginine, which forms a $\pi$-cation stack on the $3^{\prime}$-terminal uracil nucleobase and makes a hydrogen bond to the ribose $2^{\prime}-\mathrm{OH}$ of the penultimate uridine nucleoside (Fig. 1B), we introduced changes to lysine and glutamine and tested them for $1 s m 3 \Delta$ complementation. Whereas LSM3-R69K cells survived FOA selection, they were very sick, i.e., forming tiny colonies at $18^{\circ} \mathrm{C}-30^{\circ} \mathrm{C}$ and failing to grow at $37^{\circ} \mathrm{C}$ (Supplemental Fig. S1). In contrast, the LSM3-R69Q mutation was lethal. Thus, we surmise that positive charge, and arginine particularly (via its dual contacts to the ribose and uracil at the U6 $3^{\prime}$ end), are the key requirements at this position for Lsm3 function in vivo. The only other allele displaying an overt growth phenotype was $L S M 2-R 63 A$, which was extremely sick, forming tiny colonies at $18^{\circ} \mathrm{C}-25^{\circ} \mathrm{C}$ and no visible colonies at $30^{\circ} \mathrm{C}-37^{\circ} \mathrm{C}$ (Supplemental Fig. S1). Lsm2-Arg63 makes ribose and uracil interactions similar to Lsm3-Arg69, albeit to the third and second nucleosides from the $3^{\prime}$ end of U6 RNA (Fig. 1B). LSM2$R 63 \mathrm{~K}$ cells grew as well as wild-type, whereas the R63Q allele phenocopied R63A (Fig. 2B; Supplemental Fig. S1). Thus, positive charge is necessary (and apparently sufficient for vegetative growth) at this position of Lsm2.

In vitro U6 $3^{\prime}$-RNA binding experiments had shown that Lsm3-R69A and Lsm2-R63A were, by far, the most deleterious of the 21 alanine mutations of the Lsm triad residues, eliciting approximately 800 - and 400 -fold increases in the $K_{\mathrm{d}}$ for U6 3'-RNA binding vis-à-vis wild-type (Zhou et al. 2014a). Single-alanine mutations of the four other triad residues in $\mathrm{Lsm} 3$ (H36A and N38A) and Lsm2 (F35A and N37A) increased the $K_{\mathrm{d}}$ for U6 $3^{\prime}$-RNA by approximately 60- to 100-fold in vitro (Zhou et al. 2014a) yet did not overtly compromise yeast vegetative growth in our experiments. We proceeded to test double-alanine mutants of the inessential Lsm3 and Lsm2 triad residues. The LSM3(H36A-N38A) strain recovered after plasmid shuffle was very sick, forming tiny colonies on YPD agar at low temperatures and failing to grow at $30^{\circ} \mathrm{C}-37^{\circ} \mathrm{C}$ (Supplemental Fig. $\mathrm{S} 1)$. The $L S M 2-(F 35 A-N 37 A)$ strain grew well at low temperatures but slowly at $34^{\circ} \mathrm{C}-37^{\circ} \mathrm{C}$, as gauged by colony size (Supplemental Fig. S1).

It is conceivable that there is a high threshold for loss of 3'-U6 binding by Lsm2-8 before cell growth is affected. Alternatively, the mutational effects on binding to an 8-mer U6 $3^{\prime}$ RNA oligonucleotide in vitro are not directly applicable to binding to genuine U6 snRNA. For example, the RNA ligand used in the in vitro experiments has a "free" $3^{\prime}-\mathrm{OH}$, $2^{\prime}$-OH end and does not have a $3^{\prime}$-terminal monophosphate group found on native yeast U6 snRNA (Lund and Dahlberg 1992; Didychuk et al. 2017). Yet another possibility is that mutational effects on U6 $3^{\prime}$-RNA binding are buffered by other interactions of the Lsm2-8 ring with the U6 snRNP, i.e., with Prp24 or other segments of the U6 snRNA.

\section{Lsm2 mutations synergize with mutations of Lsm3}

Analysis of 63 pairwise combinations of seven benign LSM2 mutations with nine benign mutations in LSM3 identified 4 instances of synthetic lethality, 50 mutant pairs that had no effect on yeast growth, and 9 pairs that caused nonlethal growth defects (Fig. 3A). The identity of the lethal Lsm2Lsm3 mutant pairs was instructive, insofar as they were confined to: (i) the synonymous aspartates (Asp33 in Lsm2; Asp34 in Lsm3) that stabilize the respective $\beta 2-\beta 3$ RNAbinding loops (Fig. 1B); (ii) the synonymous asparagines (Asn37 in Lsm2; Asn38 in Lsm3) that make hydrogen bonds to the penultimate and terminal uracil nucleobases (Fig. 1B); and (iii) combinations of the conservative Lsm2-R63K change with either of the inessential Lsm3 RNA binding triad mutations: H36A or N38A (Fig. 3A). All of the sick or very sick mutant pairs involved either the Lsm3 RNA-binding loop aspartate (Asp34) or the uridine-binding triad residues His36 and Asn38 (Fig. 3A). These results suggest that the Lsm2 RNA-binding site can suffice when the RNA interface of Lsm3 is weakened, and vice versa, but simultaneous lesions in both Lsm 2 and Lsm 3 exert synergistic effects on viability. It was also informative that mutations at the protein interface of Lsm3, targeting Asp13 (H-bond to Lsm2-Gln83 Ne), Gln31 (H-bond to Lsm2-Gln83 Ne), Glu46 (H-bond to Lsm2-Tyr69 $\mathrm{OH}$ ), Arg61 (salt-bridge to Lsm2-Glu24), Ser77 (H-bond to Lsm6-Asp70 main chain carbonyl), and Thr78 (H-bond to Lsm6-Ser69 O $\gamma$ ) had no effect on growth in combination with any of the Lsm 2 mutations. On the Lsm 2 side of the subunit interface, whereas the $E 24 \mathrm{~A}$ change had no synergies with Lsm3 mutations, the Y69A and Q83A alleles were synthetically sick solely with the LSM3-N38A allele (Fig. 3A).

\section{Sporadic synthetic interactions of Lsm2 with Lsm4, Lsm5, and Lsm8}

Tests of 56 pairwise combinations of seven benign LSM2 mutations with eight benign mutations in LSM4 revealed no lethal combinations, 3 synthetic sick mutant pairs, 5 pairs that elicited a temperature-sensitive (ts) growth phenotype, and 48 mutant pairs that had no apparent effect on vegetative growth (Fig. 3B). The modest growth defects involved truncation of the Lsm4 C terminus (the $C \Delta 92$ allele being sick with LSM2-D33A and -R63K) and the LSM4-K20A mutation, which was either ts or sick in combination with each of the four LSM2 RNA-binding loop mutants (D33A, F35A, N37A, $R 63 K)$. Lsm4-Lys20 is located at the subunit interface with Lsm8, where it makes bifurcated H-bonds to Lsm8-Ser59 and -Glu60. It is conceivable that the Lsm4-K20A change impacts the Lsm8 subunit (the neighbor of Lsm2) and perturbs its protein-protein contacts with the Lsm2-Arg63 side chain (via H-bonds from Lsm8-Thr34 $\mathrm{O} \gamma$ to Lsm2-Arg63 $\mathrm{N} \varepsilon$ and from the Lsm8-Asn33 main chain carbonyl to Lsm2-Arg63 NH1). A key point is that there is no synergy between mutations of the RNA triad residues of Lsm4 (Trp35, Asn37, Arg72, which 


\begin{tabular}{|c|c|c|c|c|c|c|c|}
\hline A LSM3 VS LSM2 & E24A & D33A & F35A & N37A & R63K & Y69A & Q83A \\
\hline D13A & & & & & & & \\
\hline Q31A & & & & & & & \\
\hline D34A & & lethal & & sick & very sick & & \\
\hline H36A & & sick & very sick & very sick & lethal & & \\
\hline N38A & & very sick & very sick & lethal & lethal & sick & sick \\
\hline E46A & & & & & & & \\
\hline R61A & & & & & & & \\
\hline S77A & & & & & & & \\
\hline T78A & & & & & & & \\
\hline
\end{tabular}

B

\begin{tabular}{|c|c|c|c|c|c|c|c|}
\hline LSM4 vs LSM2 & $E 24 A$ & $D 33 A$ & $F 35 A$ & N37A & $R 63 K$ & Y69A & Q83A \\
\hline K20A & & ts & ts & ts & sick & & \\
\hline E23A & & & & & & & \\
\hline$D 33 A$ & & ts & & & & & \\
\hline W35A & & & & & & & \\
\hline N37A & & & & & & & \\
\hline$E 45 A$ & & & & & & & \\
\hline$R 72 A$ & ts, cs & & & & & & \\
\hline$C \Delta 92$ & & sick & & & sick & & \\
\hline
\end{tabular}

C

\begin{tabular}{|c|c|c|c|c|}
\hline LSM5 VS LSM2 & D33A & F35A & N37A & R63K \\
\hline D38A & & & & \\
\hline F40A & & & & sick \\
\hline N42A & & & sick & sick \\
\hline S74A & & & & \\
\hline
\end{tabular}

D

\begin{tabular}{|c|c|c|c|c|}
\hline LSM8 vS LSM2 & D33A & F35A & N37A & R63K \\
\hline D31A & & & & \\
\hline N33A & & & & \\
\hline N35A & & & & \\
\hline R57A & & & & sick \\
\hline
\end{tabular}

FIGURE 3. Mutational synergies with $l s m 2 \Delta$. (A-D) Synthetically lethal pairs of alleles are highlighted in red boxes. Other negative pairwise interactions are classified as sick or very sick (yellow boxes), or temperature-sensitive ( $t s$ ) or cold-sensitive (cs) (light green boxes). Gray boxes denote lack of mutational synergy.

contact the first $\mathrm{U}$ in the $5^{\prime}$-GUUUU RNA in the crystal structure) and Lsm2 (Phe35, Asn37, Arg63).

Based on the results of pairwise testing in Figure $3 \mathrm{~A}$ and B, we limited subsequent synthetic interaction screening to the LSM2 RNA loop alleles D33A, F35A, N37A, and R63K and their equivalents in LSM5 and LSM8. This analysis of 32 mutant pairs disclosed no cases of synthetic lethality, four instances of synthetic sickness (three of which involved LSM2-R63K), and 28 mutant pairs that had no effect on yeast growth (Fig. 3C,D).

\section{Synthetic interactions of Lsm3 with Lsm4, Lsm5, and Lsm8}

Tests of 36 pairwise combinations of the three benign LSM3 RNA-binding loop mutants (D34A, H36A, N38A) with the RNA-binding loop mutants of LSM4, LSM5, and LSM8 yielded 2 synthetically lethal mutant pairs (of LSM3-N38A with LSM8-N35A and -R57A), 16 synthetic sick or very sick mutant combinations (15 of which involved LSM3-H36A and $-N 38 A$ ), 7 cases of ts growth (mostly involving LSM3-D34A), and 11 mutant pairs without effect on growth (Fig. 4AC). The distribution of synthetic interactions highlights functional overlap between the RNA-binding site of Lsm3 (at the $3^{\prime}$ terminal uridine) and those of Lsm8 and Lsm4 (at the uridines two and three positions upstream, respectively). The fewer number, and lesser severity, of Lsm3 synergies with Lsm5 is consistent with the absence of Lsm 5 contacts to the terminus of U6 snRNA in the crystal structure.

\section{Paucity of synthetic interactions among Lsm4, Lsm5, and Lsm8}

Tests of 16 pairwise combinations of RNA-binding loop mutants of Lsm4 and Lsm5 revealed no effects on yeast growth (Fig. 4D). Similarly, 16 pairwise combinations of LSM5 and LSM8 alleles elicited no growth defects (Fig. 4F). Of the 16 pairs of LSM4 and LSM8 mutants tested, 15 were benign and only one resulted in a ts phenotype, by virtue of alanine substitutions for the RNA-binding loop aspartates Lsm8-Asp31 and Lsm4-Asp33 (Fig. 4E).

\section{Bypass of essential Lsm subunits by overexpression of U6 snRNA}

The Lsm2-8 ring decorates the U6 snRNA in the yeast U4/ U6.U5 tri-snRNP (Nguyen et al. 2016) and the yeast precatalytic spliceosome (B complex) (Plaschka et al. 2017), but is ejected during the formation of the catalytic spliceosome ( $\mathrm{B}^{\text {act }}$ complex) (Chan et al. 2003). Thus, the Lsm2-8 ring is not required during the splicing transesterification reactions. Early findings that U6 snRNA levels are reduced in Lsm mutant backgrounds prompted experiments showing that increased U6 expression (via increased U6 gene dosage on a high copy $2 \mu$ plasmid) could compensate for growthdefective Lsm mutations. For example, Pannone et al. (2001) reported that $2 \mu$-U6 allowed the recovery of $l s m 8 \Delta$ haploids after sporulation and tetrad dissection of a LSM8 $1 \operatorname{sm} 8 \Delta$ diploid strain. The $l s m 8 \Delta 2 \mu$-U6 segregants were smaller than their wild-type tetrad mates grown at $30^{\circ} \mathrm{C}$, but were 
A

\begin{tabular}{|c|c|c|c|}
\hline LSM4 vs LSM3 & D34A & H36A & N38A \\
\hline D33A & sick & sick & very sick \\
\hline W35A & ts & very sick & very sick \\
\hline N37A & ts & very sick & very sick \\
\hline R72A & ts & very sick & very sick \\
\hline
\end{tabular}

B

\begin{tabular}{|c|c|c|c|}
\hline LSM5 VS LSM3 & D34A & H36A & N38A \\
\hline D38A & & sick & ts \\
\hline F40A & & sick & sick \\
\hline N42A & & & ts \\
\hline S74A & & & \\
\hline
\end{tabular}

C

\begin{tabular}{|c|c|c|c|}
\hline LSM8 vS LSM3 & D34A & H36A & N38A \\
\hline D31A & ts & & sick \\
\hline N33A & & & sick \\
\hline N35A & ts & very sick & lethal \\
\hline R57A & & very sick & lethal \\
\hline
\end{tabular}

\begin{tabular}{|c|c|c|c|c|}
\hline LSM5 VS LSM4 & D33A & W35A & N37A & R72A \\
\hline D38A & & & & \\
\hline F40A & & & & \\
\hline N42A & & & & \\
\hline S74A & & & & \\
\hline
\end{tabular}

E

\begin{tabular}{|c|c|c|c|c|}
\hline LSM8 vS LSM4 & D33A & W35A & N37A & R72A \\
\hline D31A & ts & & & \\
\hline N33A & & & & \\
\hline N35A & & & & \\
\hline R57A & & & & \\
\hline
\end{tabular}

$\mathbf{F}$

\begin{tabular}{|c|c|c|c|c|}
\hline LSM8 vS LSM5 & D38A & F40A & N42A & S74A \\
\hline D31A & & & & \\
\hline N33A & & & & \\
\hline N35A & & & & \\
\hline R57A & & & & \\
\hline
\end{tabular}

FIGURE 4. Intersubunit synthetic genetic interactions. $(A-F)$ Synthetically lethal pairs of alleles are highlighted in red boxes. Other negative pairwise interactions are classified as sick or very sick (yellow boxes), or temperature-sensitive ( $t s$ ) or cold sensitive (cs) (light green boxes). Gray boxes denote lack of mutational synergy.

not characterized further, leaving open the question of whether they were impaired in germination or in vegetative growth. Mayes et al. (1999) found that high-copy U6 partially suppressed the ts growth defect of $l s m 6 \Delta$ and $l s m 7 \Delta$ cells at $37^{\circ} \mathrm{C}$ and rescued, to varying degrees, the growth defects on glucose-repressive medium of cells in which the LSM2, LSM3, LSM4, LSM5, or LSM8 were under the control of the GAL1 promoter.

Our aim here was to evaluate the effects of U6 overexpression in all five of the essential $l s m \Delta$ genetic backgrounds. The lsm $\triangle \mathrm{p}$ [CEN LSM URA3] strains were transformed with either a cognate CEN LSM LEU2 plasmid or with a $2 \mu-U 6$ $L E U 2$ plasmid. All five $l s m \Delta 2 \mu$-U6 transformants survived FOA selection against the LSM URA3 plasmid. The lsm $\Delta$ $2 \mu$-U6 strains were spot-tested for growth on YPD agar (Fig. 5). Whereas all of the $l s m \Delta 2 \mu$-U6 strains thrived at lower growth temperatures, they displayed varying degrees of temperature sensitivity (as gauged by colony size), ranging from slower growth at $30^{\circ} \mathrm{C}-34^{\circ} \mathrm{C}$ plus severe sickness at $37^{\circ} \mathrm{C}$ for $l s m 2 \Delta$, $l s m 3 \Delta$, and $l s m 4 \Delta$, to modestly slowed growth at $30^{\circ} \mathrm{C}-37^{\circ} \mathrm{C}$ for $l s m 8 \Delta$ and $l s m 5 \Delta$ (Fig. 5). Primer extension analysis of the level of U6 snRNA (and of U5 snRNA as an internal control) in wild-type cells and in $1 s m 3 \Delta$ $2 \mu$-U6 cells affirmed that U6 snRNA was indeed overexpressed from the multicopy plasmid (Supplemental Fig. S2, by 5.7fold compared to the wild-type U6 level).

\section{U6 overexpression bypasses Ism $\Delta$ Ism $\Delta$ double-deletions and $I s m \Delta I s m \Delta / s m \Delta$ triple-deletions}

The ability of U6 overexpression to bypass the individual essential Lsm subunits is consistent with any of several scenarios, to wit: (i) an incomplete ring composed of six Lsm subunits can support U6 function when assembly of a U6 snRNP is driven by increased U6 snRNA production; (ii) another Lsm subunit can fill the slot in the Lsm ring that is vacated when one of the Lsm subunits is deleted and thereby allows the formation of an aberrant but functional U6 snRNP when U6 snRNA production is increased; or (iii) increased U6 snRNA production elides the need for the Lsm ring in its entirety. If the first scenario is operative, then we

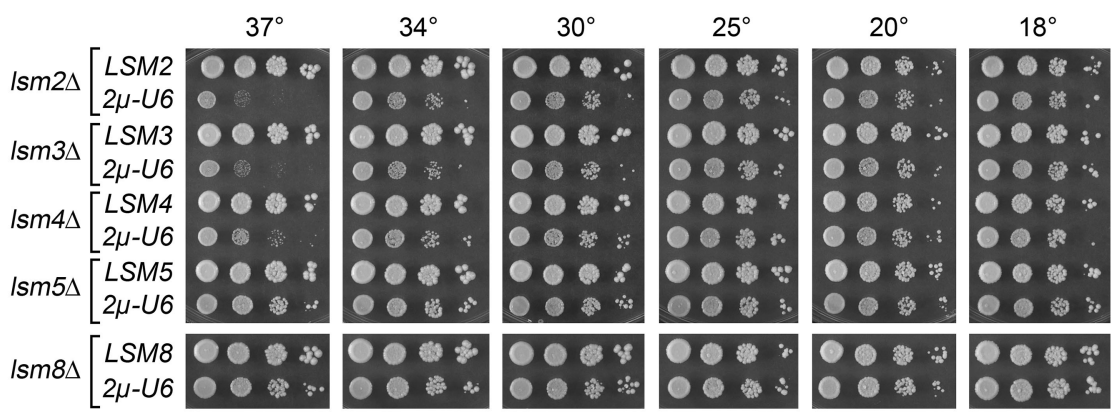

FIGURE 5. Bypass of essential Lsm subunits by U6 snRNA overexpression. The indicated lsms strains were tested by plasmid shuffle for complementation by the corresponding wild-type LSM genes (as positive controls) and for bypass by a $2 \mu$-U6 plasmid. The viable FOA-resistant $l s m \Delta$ $\mathrm{p}[C E N L S M]$ and $l s m \Delta \mathrm{p}[2 \mu-U 6]$ strains were spot-tested for growth on YPD agar at the temperatures specified. 
would expect that simultaneous elimination of any two of the seven Lsm ring subunits (and especially loss of two subunits that are not contiguous within the Lsm ring) prevents formation of functional Lsm complex on U6 snRNA, so that at least some of the $l s m \Delta l s m \Delta$ double deletions will not be bypassed by U6 overexpression. In contrast, if the third scenario applies, then U6 overexpression will rescue the lethality of any and all $l s m \Delta l s m \Delta$ pairwise deletants.

To test these predictions, we generated $10 \operatorname{lsm} \Delta \operatorname{lsm} \Delta$ double-deletion mutants, comprising all pairwise combinations of null alleles of the five essential $L S M$ genes, the viability of which was sustained by cognate CEN URA3 LSM LSM plasmids. We subjected them to plasmid shuffle with either marked $C E N$ plasmids bearing the respective $L S M$ genes (as a positive control) or a $2 \mu L E U 2$ U6 plasmid. Overexpression of U6 snRNA allowed for FOA-resistant growth of all 10 lethal $l s m \Delta l s m \Delta$ test strains. The $l s m \Delta$ lsm $2 \mu$-U6 strains grew fairly well at $18^{\circ} \mathrm{C}, 20^{\circ} \mathrm{C}$, and $25^{\circ} \mathrm{C}$, yet they formed smaller colonies at $30^{\circ} \mathrm{C}$ or $34^{\circ} \mathrm{C}$, and were all grossly defective for growth at $37^{\circ} \mathrm{C}$ compared to the CEN LSM LSM positive control strains (Fig. 6A). We also constructed a double-deletion of the two inessential LSM genes (encoding the Lsm6 and Lsm7 subunits), and found that they were synthetically lethal. Plasmid shuffle into the $l s m 6 \Delta l s m 7 \Delta \mathrm{p}[C E N$ URA3 LSM6] strain resulted in recovery of FOA-resistant $l s m 6 \Delta \operatorname{lsm} 7 \Delta \mathrm{p}[2 \mu-U 6]$ cells that grew as well as the lsm6 $l s m 7 \Delta \mathrm{p}$ [CEN LSM6 LSM7] positive control at $18^{\circ} \mathrm{C}-34^{\circ} \mathrm{C}$, while growing poorly at $37^{\circ} \mathrm{C}$ (Fig. 6A).

We extended this approach to a series of $l s m \Delta l \operatorname{lsm} \Delta \operatorname{lsm} \Delta$ triple-deletion mutants and found that a $2 \mu$-U6 plasmid sustained the viability of $l s m 2 \Delta l s m 3 \Delta l s m 4 \Delta, l s m 2 \Delta l s m 3 \Delta$ $l s m 5 \Delta$, and $l s m 2 \Delta l s m 3 \Delta l s m 8 \Delta$ strains. Here too, the $l s m \Delta$ lsm $\operatorname{lsm} \Delta 2 \mu$-U6 strains grew well at $18^{\circ} \mathrm{C}, 20^{\circ} \mathrm{C}$, and $25^{\circ} \mathrm{C}$, and formed smaller colonies at $30^{\circ} \mathrm{C}-37^{\circ} \mathrm{C}$ compared to an LSM wild-type control (Fig. 6B). We conclude from these experiments that overexpression of U6 snRNA (affirmed by primer extension analysis of RNA from the $\operatorname{lsm} 2 \Delta \operatorname{lsm} 3 \Delta$ $2 \mu$-U6 and $l s m 2 \Delta l s m 3 \Delta l s m 4 \Delta 2 \mu$-U6 strains, in which U6 was overexpressed by seven- and 13-fold, respectively; see Supplemental Fig. S2) bypasses the essentiality of the Lsm2-8 ring for vegetative growth.

\section{Defective SUS1 and MATa1 splicing in $2 \mu$-U6 bypassed Ism234 $\Delta$ cells at restrictive temperature}

To test whether the $2 \mu$-U6-bypassed $l s m 2 \Delta l s m 3 \Delta l s m 4 \Delta$ cells incurred a defect in pre-mRNA splicing, we assayed the efficacy of in vivo splicing of the yeast SUS1 and MATa1 pre-mRNAs. We chose SUS1 in light of prior findings that
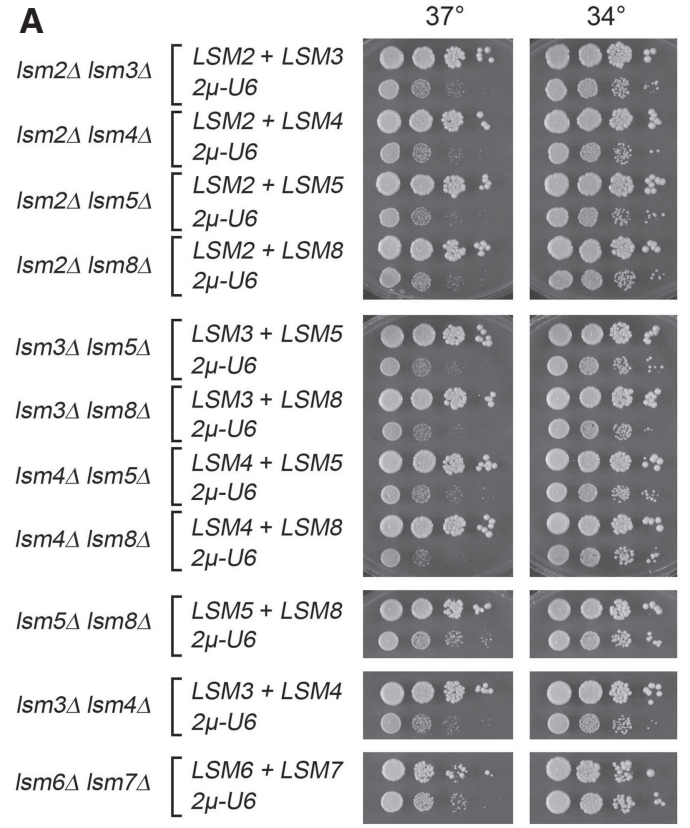

B $2 \mu-U 6\left[\begin{array}{c}W T \\ I s m 2 \Delta / s m 3 \Delta / s m 4 \Delta \\ I s m 2 \Delta / s m 3 \Delta / s m 5 \Delta \\ I s m 2 \Delta / s m 3 \Delta / s m 8 \Delta\end{array}\right.$

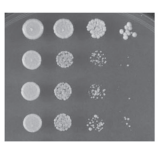

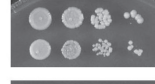
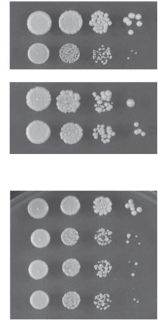

$30^{\circ}$
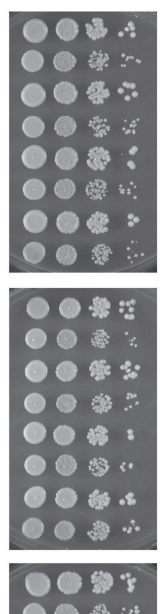

$25^{\circ}$
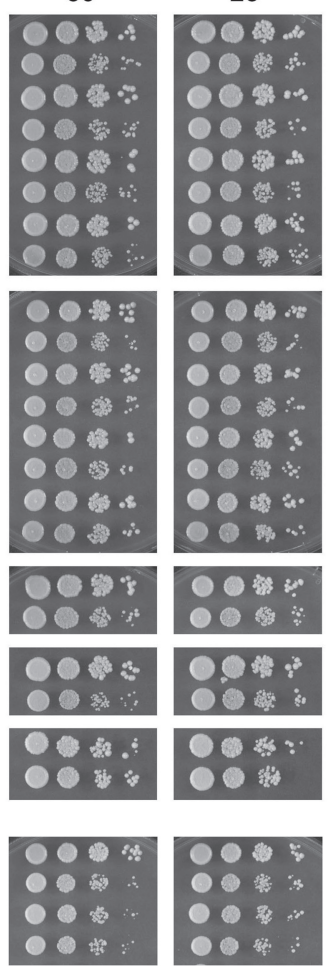

$20^{\circ}$
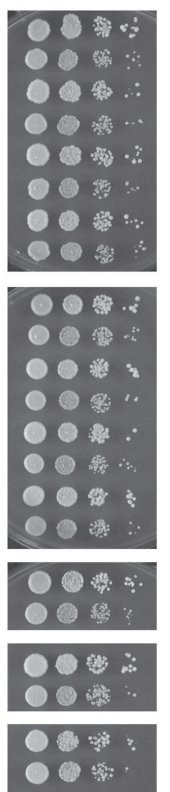

$18^{\circ}$
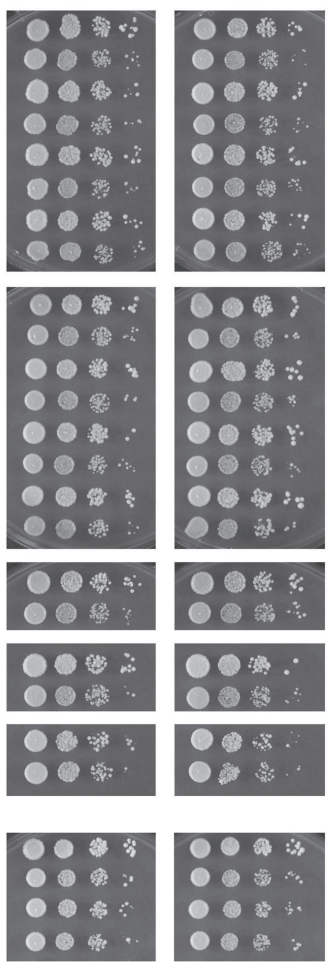

FIGURE 6. Bypass of $l s m$ double and triple deletions by U6 snRNA overexpression. (A) The indicated $l s m \Delta l s m \Delta$ strains were tested by plasmid shuffle for complementation by the corresponding pairs of wild-type $L S M$ genes (as positive controls) and for bypass by a $2 \mu$ - $U 6$ plasmid. The viable FOAresistant controls and the $l s m \Delta l s m \Delta \mathrm{p}[2 \mu$-U6] strains were spot-tested for growth on YPD agar at the temperatures specified. (B) The indicated tripledeletion strains harboring a $2 \mu$-U6 plasmid were spot-tested for growth on YPD agar in parallel with a wild-type strain. 
SUS1 splicing is adversely affected by a mutation in the $\mathrm{m}^{7} \mathrm{G}$ cap binding pocket of the nuclear cap-binding protein $\mathrm{Cbc} 2$ (Qiu et al. 2012), by mutations in the branchpoint binding protein Msl5 that perturb the Msl5.branchpoint RNA interface (Jacewicz et al. 2015), and by mutations in the U1 snRNP subunit Luc7 (Agarwal et al. 2016). SUS1 is one of a handful of yeast genes that contain two introns, and it is the splicing of the first intron (which has a nonconsensus $5^{\prime}$ splice site GUAUGA and a nonconsensus branchpoint sequence UACUGAC) that is selectively impaired in the aforementioned strain backgrounds (Hossain et al. 2009; Qiu et al. 2012). The MATal pre-mRNA also contains two introns, albeit both with consensus splicing signals. Mutations in Msl5 cause a selective impediment to the splicing of the second intron of the MATal pre-mRNA (Jacewicz et al. 2015). As a control, we gauged the splicing of GLC7, which has a single intron and is efficiently spliced in wild-type cells and all of the aforementioned mutants. cDNAs were synthesized by oligo $(\mathrm{dT})$-primed reverse transcription of total RNA from: (i) wild-type cells and $l s m 2 \Delta l s m 3 \Delta l s m 4 \Delta 2 \mu$-U6 cells grown in YPD broth at $30^{\circ} \mathrm{C}$; and (ii) wild-type cells and $1 \operatorname{sm} 2 \Delta$ lsm $3 \Delta l s m 4 \Delta 2 \mu-U 6$ cells grown at $30^{\circ} \mathrm{C}$ and then shifted to $37^{\circ} \mathrm{C}$ for $4 \mathrm{~h}$. The cDNAs were then PCR-amplified using gene-specific primer pairs in the first and last exons, such that agarose gel electrophoresis would resolve the longer PCR fragments derived from unspliced pre-mRNA (which comigrates with the control fragment amplified from a genomic DNA template) and the shorter PCR fragments derived from mature spliced mRNA or, in the case of SUS1 and MATa1, singly spliced intermediates (Supplemental Fig. S3).

As shown in Supplemental Figure S3A, SUS1 transcripts in wild-type cells at $30^{\circ} \mathrm{C}$ or $37^{\circ} \mathrm{C}$ consisted predominantly of mature mRNA plus a minority population of singly spliced intermediate species and unspliced pre-mRNA. In $l s m 234 \Delta 2 \mu$-U6 cells, there was a slight increase in the level of unspliced SUS1 pre-mRNA at $30^{\circ} \mathrm{C}$ (a semi-permissive temperature). The instructive finding was that shift of $l s m 234 \Delta 2 \mu$-U6 cells to $37^{\circ} \mathrm{C}$ caused accumulation of unspliced SUS1 pre-mRNA accompanied by a decrease in the proportion of spliced mRNA, to the degree that the unspliced pre-mRNA and the singly spliced intermediate together comprised the majority species (Supplemental Fig. S3A). Supplemental Figure S3B reveals similar findings for MATa1 splicing, whereby the doubly spliced mature mRNA was the majority species in wild-type cells at $30^{\circ} \mathrm{C}$ or $37^{\circ} \mathrm{C}$, with a minority of singly spliced intermediate and little or no unspliced precursor. $l s m 234 \Delta 2 \mu-U 6$ cells at $30^{\circ} \mathrm{C}$ showed a decrement in spliced MATal mRNA and the onset of appearance of unspliced precursor; this was exacerbated after shift to $37^{\circ} \mathrm{C}$, such that the singly spliced intermediate predominated at the expense of mature mRNA and with a further increase in unspliced precursor (Supplemental Fig. S3B). In contrast, GLC7 mRNA splicing occurred with virtually complete efficiency in wild-type and $1 \operatorname{sm} 234 \Delta 2 \mu$-U6 cells regardless of the growth temperature.

\section{Overexpression of one Lsm subunit does not compensate for loss of another Lsm subunit}

To attempt to address whether a vacancy of an essential "slot" in the Lsm2-8 ring can be filled functionally by overexpressing any of the other essential subunits, we tested for complementation of the five lethal $l s m \Delta$ alleles by $2 \mu$ plasmids bearing LSM2, LSM3, LSM4, LSM5, or LSM8 (Supplemental Fig. $S 4 \mathrm{~A})$. Controls verified that each $2 \mu-L S M$ plasmid complemented its cognate $l s m \Delta$ strain. However, none of the $\operatorname{lsm} \Delta$ mutations were complemented by a $2 \mu$ plasmid expressing a noncognate Lsm subunit, with the single exceptions of $l s m 5 \Delta$ being very weakly rescued by overexpression of Lsm 4 and Lsm8, such that $l s m 5 \Delta 2 \mu$-LSM8 cells formed tiny colonies at $25^{\circ} \mathrm{C}, 1 s m 5 \Delta 2 \mu$-LSM 4 cells formed scant microscopic colonies at $25^{\circ} \mathrm{C}$, and both strains failed to grow at $37^{\circ} \mathrm{C}$ (Supplemental Fig. S4B).

\section{Bypass of prp24 $\Delta$ by overexpression of U6 snRNA}

The 444-aa Prp24 protein is essential for viability of S. cerevisiae and is a defining component of the U6 snRNP. Prp24, which consists of four RRM domains and a C-terminal peptide that interacts with the Lsm2-8 ring (Rader and Guthrie 2002; Montemayor et al. 2014, 2017), functions together with the Lsm ring to promote the annealing of U4 and U6 snRNAs during formation of a U4/U6 di-snRNP (Raghunathan and Guthrie 1998; Didychuk et al. 2016). Having found that U6 snRNA overexpression bypasses the essential Lsm subunits of the U6 snRNP, we proceeded to ask whether Prp24 could also be rendered dispensable by U6 overexpression. A prp24 $\triangle$ $\mathrm{p}$ [CEN URA3 PRP24] strain that was unable to form colonies in the presence of FOA was transformed with either a $2 \mu$ PRP24 LEU2 plasmid or a $2 \mu-U 6 L E U 2$ plasmid, either of which conferred the ability to form FOA-resistant colonies. The prp24 $2 \mu$-U6 strain (which overexpressed U6 snRNA by 14-fold; Supplemental Fig. S2) grew on YPD agar at $37^{\circ} \mathrm{C}, 34^{\circ} \mathrm{C}, 30^{\circ} \mathrm{C}$, and $25^{\circ} \mathrm{C}$, albeit more slowly than the PRP24-complemented control strain, as gauged by colony size (Fig. 7A). prp24 $2 \mu$-U6 cells failed to grow at lower temperatures, $20^{\circ} \mathrm{C}$ and $18^{\circ} \mathrm{C}$ (Fig. 7A). The cold-sensitive (cs) phenotype of prp24 $2 \mu$-U6 cells (Fig. 7A) contrasts with the ts growth defects of the various $\operatorname{lsm} \Delta \operatorname{lsm} \Delta 2 \mu$-U6 strains (Fig. 6A), suggesting that different aspects of U6 snRNP function become limiting for growth when U6 snRNA overexpression compensates for absence of the U6-associated Lsm ring versus the U6 snRNP subunit Prp24.

\section{Bypass of Ism $\Delta$ by overexpression of Prp24}

We closed the circle on the genetic nexus between the components of the U6 snRNP by querying whether overexpressing Prp24 might bypass the essentiality of the U6-associated Lsm ring subunits. We found that all five of the lethal $l s m \Delta$ mutations were suppressed by transformation with a $2 \mu$ 


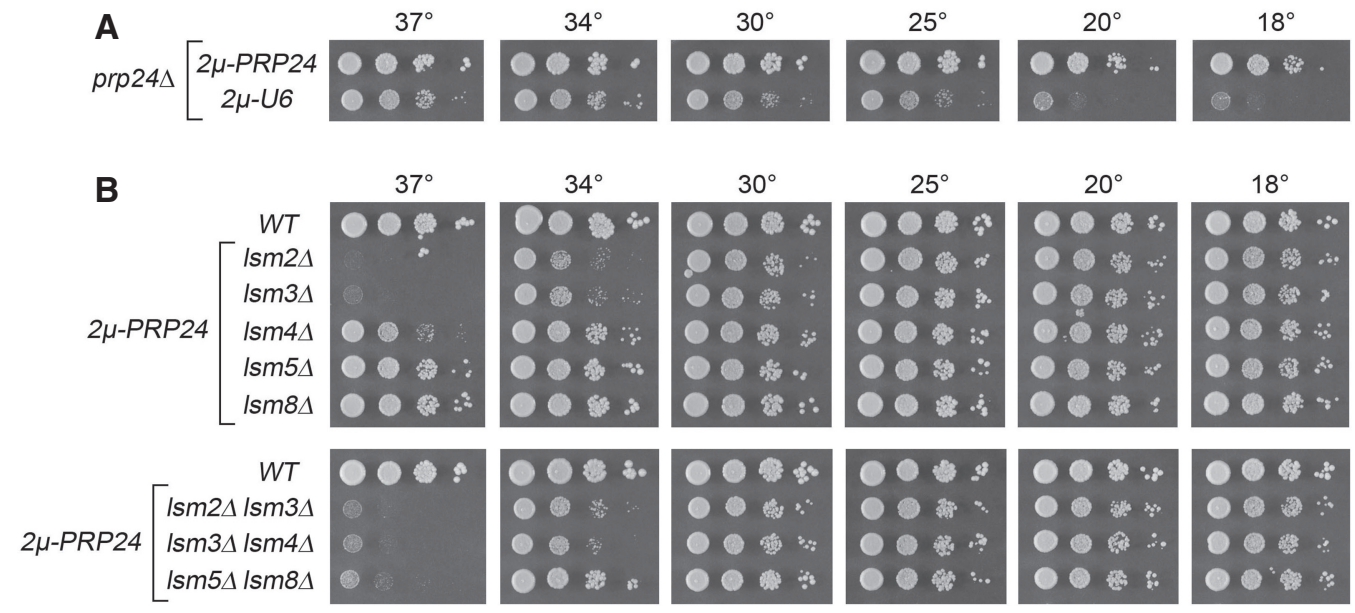

FIGURE 7. Bypass of prp $24 \Delta$ by U6 overexpression and bypass of $l s m \Delta$ by Prp24 overexpression. (A) prp24D p [URA3 CEN PRP24] cells were tested by plasmid shuffle for complementation by a $2 \mu$ PRP24 plasmid (as positive control) and for bypass by a $2 \mu-U 6$ plasmid. (B) The indicated $l s m \Delta$ and $l s m \Delta l s m \Delta$ strains were tested by plasmid shuffle for bypass by a $2 \mu$-PRP24 plasmid. The viable FOA-resistant strains were spot-tested for growth on YPD agar at the temperatures specified.

LEU2 PRP24 plasmid (in which PRP24 expression is driven by the TPI1 promoter) prior to plasmid shuffle to eliminate the growth-sustaining CEN URA3 LSM plasmid. The lsm5 $2 \mu$-PRP24 and $l s m 8 \triangle 2 \mu$-PRP24 strains grew well on YPD agar at $18^{\circ} \mathrm{C}-37^{\circ} \mathrm{C}$ (Fig. $\left.7 \mathrm{~B}\right) .1 s m 4 \Delta 2 \mu-P R P 24$ cells thrived at $18^{\circ} \mathrm{C}-34^{\circ} \mathrm{C}$ but were sick at $37^{\circ} \mathrm{C}$ (Fig. 7B). The $l s m 2 \Delta$ $2 \mu$-PRP24 and $l s m 3 \triangle 2 \mu-P R P 24$ strains grew at lower temperatures, but were sick at $34^{\circ} \mathrm{C}$ and failed to grow at $37^{\circ} \mathrm{C}$ (Fig. 7B). The growth phenotypes of the various $2 \mu$-PRP24 bypassed $l s m \Delta$ mutants echoes what was seen for the $2 \mu$-U6 bypass of $l s m \Delta$ (Fig. 5 ).

Prp24 overexpression also bypassed the lethality of doublemutants $l s m 2 \Delta l s m 3 \Delta$, $l s m 3 \Delta l s m 4 \Delta$, and $l s m 5 \Delta l s m 8 \Delta$ (Fig. 7B) and triple-mutants $l \operatorname{sm} 2 \Delta l \operatorname{sm} 3 \Delta l \operatorname{sm} 4 \Delta$, $l \operatorname{sm} 2 \Delta l \operatorname{sm} 3 \Delta$ $l s m 5 \Delta$, and $l s m 2 \Delta l s m 3 \Delta l s m 8 \Delta$ (not shown). The $l s m \Delta l s m \Delta$ $2 \mu$-PRP24 strains grew well on YPD agar at $18^{\circ} \mathrm{C}-30^{\circ} \mathrm{C}$, but were ts and did not thrive at $37^{\circ} \mathrm{C}$ (Fig. 7B).

Because Prp24 collaborates with the Lsm2-8 ring to catalyze the annealing of U4 and U6 snRNAs during formation of a U4/U6 di-snRNP (Didychuk et al. 2016), it was of interest to determine if U4 and U6 do form a stable U4/U6 hybrid in: (i) cells lacking essential Lsm subunits or Prp24 that depend on U6 overexpression for viability; and (ii) cells lacking Lsm subunits that rely on Prp24 overexpression for viability. To detect the U4/U6 hybrid, we exploited the method of Brow and colleagues (Li and Brow 1993; Burke et al. 2015) whereby yeast RNA is isolated under nondenaturing conditions and then hybridized in solution at $42^{\circ} \mathrm{C}$ to a ${ }^{32} \mathrm{P}$-labeled oligonucleotide complementary to a segment of the U4 snRNA. Analysis of the samples by native gel electrophoresis separates probe annealed to the U4/U6 hybrid from probe annealed to U4 snRNA. As shown in the experiments in Supplemental Figures S5 and S6, in which we used a ${ }^{32} \mathrm{P}$-labeled probe complementary to $\mathrm{U} 4$ snRNA positions $77-91$ ( $\mathrm{Li}$ and Brow
1993), virtually all of the U4 probe that was annealed to RNA isolated from wild-type cells was in the form of U4/ U6 hybrid. When the isolated RNA was heated at $70^{\circ} \mathrm{C}$ prior to incubation with the probe at $42^{\circ} \mathrm{C}, 95 \%$ of the $\mathrm{U} 4$ probe annealed to the more rapidly migrating free U4 snRNA (Supplemental Fig. S5). When native RNA was annealed to a ${ }^{32} \mathrm{P}$-labeled probe complementary to U6 snRNA positions 92-112, two species were resolved, corresponding to U4/U6 hybrid and free U6, respectively (Supplemental Fig. S5). Quantification of the signal indicated that $36 \%$ of the U6 signal was present as U4/U6 hybrid. After heat denaturation of the RNA, the U6 probe annealed virtually exclusively to the more rapidly migrating free U6 (Supplemental Figs. S5 and S7). As an additional control, we used a ${ }^{32} \mathrm{P}$-labeled probe complementary to U5 snRNA positions $158-180$, which annealed to a closely spaced doublet corresponding to the long (214-nt) and short (179-nt) forms of the yeast U5 snRNA that differ at their $3^{\prime}$ ends. Note that the mobility of the U5 probe annealing to the U5 RNAs was not affected by prior heat denaturation (Supplemental Fig. S5).

In cells lacking one, two, or three Lsm subunits that overexpressed U6 snRNA, and in cells lacking Prp24 that overexpressed U6 snRNA, it was still the case that the majority of the U4 probe annealed to a U4/U6 hybrid, though $11 \%-$ $12 \%$ of the probe annealed to the more rapidly migrating U4 snRNA (Supplemental Fig. S6). When the same analysis was performed with a U6 probe, we detected the U4/U6 hybrid at levels similar to the wild-type strain, as well as much higher levels of free U6 snRNA reflective of its overexpression from the $2 \mu$ plasmid (Supplemental Fig. S7). We envision that increasing the steady-state levels of U6 snRNA in the $2 \mu$-U6 strains (Supplemental Figs. S2 and S7) compensates by mass action to promote U4/U6 annealing in the absence of Prp24 or Lsm ring subunits. 
In cells lacking Lsm3, or Lsm2 and Lsm3, that overexpress Prp24 the fraction of probe annealing to U4 snRNA was higher (37\%-39\%), though the U4/U6 hybrid was still present (Supplemental Fig. S6). The U4/U6 hybrid was also detected with the U6 probe in these Prp24-overexpressing strains (Supplemental Fig. S7).

\section{Overexpression Prp24 suppresses lethality of usb1}

S. cerevisiae Usb1 is an essential endoribonuclease $/ 2^{\prime}, 3^{\prime}$-cyclic phosphodiesterase enzyme that processes the $3^{\prime}$ end of the U6 transcript to generate the $3^{\prime}$-monophosphate terminus found on the mature yeast U6 snRNA (Mroczek et al. 2012; Didychuk et al. 2017). Depletion of Usb1 results in destabilization of U6 snRNA in vivo. The lethality of a $u s b 1 \Delta$ knockout mutation can be rescued by U6 snRNA overexpression from a multicopy plasmid (Mroczek et al. 2012). Here we affirmed by plasmid shuffle that a $u s b 1 \Delta 2 \mu$-U6 strain was viable and that $u s b 1 \Delta 2 \mu$-U6 cells (which overexpressed U6 by eightfold [Supplemental Fig. S2] and formed the U4/U6 hybrid RNA [Supplemental Fig. S5]) grew well on YPD agar at all temperatures tested from $18^{\circ} \mathrm{C}$ to $37^{\circ} \mathrm{C}$ (Fig. 8). Our aim was to test if the need for $3^{\prime}$ processing of U6 RNA by Usb1 could be bypassed by overexpression of the U6 snRNP subunit Prp24. We found that transformation of $u s b 1 \Delta \mathrm{p}[C E N$ URA3 USB1] cells with a $2 \mu$-PRP24 plasmid enabled the recovery of viable FOA-resistant $u s b 1 \Delta 2 \mu$-PRP24 colonies and that usb1 $2 \mu$-PRP24 cells grew more slowly than USB1 (wild-type) or $u s b 1 \Delta 2 \mu$-U6 cells on YPD agar at $25^{\circ} \mathrm{C}, 30^{\circ} \mathrm{C}$, and $34^{\circ} \mathrm{C}$ (Fig. 8). usb $1 \Delta 2 \mu$-PRP24 cells did not thrive at $37^{\circ} \mathrm{C}$ or $18^{\circ} \mathrm{C}-20^{\circ} \mathrm{C}$ (Fig. 8). Thus, Prp 24 overexpression can bypass Usb1 function, albeit less effectively than it bypasses the U6-associated Lsm ring (cf. Fig. 8 and 7B) and less effectively than Usb1 is bypassed by U6 overexpression.

\section{Concluding remarks}

In this study, we have advanced in vivo structure-function analysis of the yeast Lsm2-8 ring to a level commensurate with that of the yeast Sm ring. The key findings are as follows. (i) Alanine scanning of 39 amino acids at the RNA-binding sites or intersubunit interfaces of Lsm2, Lsm3, Lsm4, Lsm5, and Lsm8 yielded only one instance of lethality (Lsm3R69A) and one severe growth defect (Lsm2-R63A), both involving amino acids that bind the $3^{\prime}$-terminal UUU trinucleotide. (ii) Tests of 235 pairwise combinations of benign Lsm mutants identified six inter-Lsm synthetic lethalities and 45 cases of nonlethal synthetic growth defects. Thus, Lsm2-8 ring function (like that of the Sm ring) is buffered by a network of genetic redundancies within the ring.

Exploration of genetic interactions of the Lsm2-8 ring with the other components of the U6 snRNP revealed that the ring is dispensable en bloc when either the U6 snRNA or the Prp24 protein is overexpressed and that Prp24 is dispensable when U6 snRNA is overexpressed. The fact that even triple-deletions of essential Lsm subunits can be rescued to virtually normal vegetative growth at $25^{\circ} \mathrm{C}$ by high-copy U6 or PRP 24 plasmids prompts the conclusion that abetting U6 snRNA is the only essential function of the Lsm2-8 ring (and of Prp24). A corollary is that the participation of the Lsm2-7 subunits in the Lsm1-7 ring that regulates RNA turnover (Tharun et al. 2000) is not essential for yeast vegetative growth, insofar as such an essential function would not be bypassed by increased U6 or PRP24 gene dosage. That Lsm double-deletions and triple-deletions display growth defects at $37^{\circ} \mathrm{C}$ when U6 snRNA is overexpressed could signify: (i) U6 snRNA function in splicing is inherently ts in the absence of the Lsm2-8 ring, e.g., as reflected in the SUS1 and MATa1 splicing defects observed in a $2 \mu$-U6 bypassed $l s m 2 \Delta l s m 3 \Delta l s m 4 \Delta$ strain after shift to the restrictive temperature; or (ii) the Lsm1-7 ring is important for growth at $37^{\circ} \mathrm{C}$. The fact that compound Lsm deletions are also ts when rescued by overexpression of Prp24 points to the U6 snRNP as the source of the conditional phenotypes.

\section{MATERIALS AND METHODS}

\section{Yeast $L S M$ expression plasmids and mutants}

A series of expression plasmids for the LSM2, LSM3, LSM4, LSM5, LSM6, LSM7, and LSM8 genes were generated by PCR amplification of segments from S. cerevisiae BY4741 genomic DNA with oligonucleotide primers that introduced restriction sites for cloning into pRS316 (URA3 CEN), pRS413 (HIS3 CEN) and pRS415 (LEU2 $C E N)$ vectors. Two-stage PCR overlap extension was used to remove the 128-nt intron from the LSM2 gene and the 96-nt intron from the LSM7 gene. The PCR products were cleaved at their termini with restriction endonucleases and then inserted into the CEN plasmids. All genes in the resulting plasmids were sequenced completely to confirm that no unwanted changes were acquired

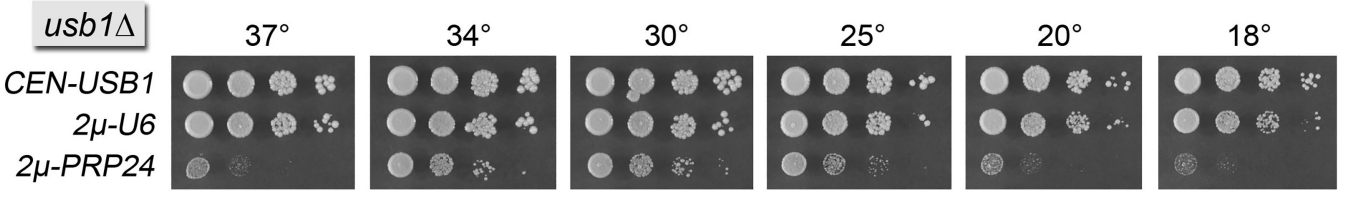

FIGURE 8. Overexpression of Prp24 suppresses lethality of usb1 $1 \Delta$. usb1 $1 \Delta$ p [URA3 CEN USB1] cells were tested by plasmid shuffle for complementation by a CEN USB1 plasmid (as positive control) and for bypass by $2 \mu-U 6$ and $2 \mu$-PRP24 plasmid. The viable FOA-resistant strains were spot-tested for growth on YPD agar at the temperatures specified. 
during amplification and cloning. The cloned LSM genes contained no nucleotide sequence polymorphisms relative to the $S$. cerevisiae S288C strain from which BY4741 is derived. We thereby generated pRS316-LSM2, pRS413-LSM2, and pRS415-LSM2, wherein the 288-bp LSM2 ORF is flanked by 349-bp and 238-bp of upstream and downstream genomic sequence. Other LSM expression plasmids harbored the LSM3 gene ( -366 to +496 , relative to the translational start codon at +1$)$, LSM4 gene $(-380$ to +785$)$, LSM5 ( -332 to +479$)$, LSM6 ( -400 to +521$)$, LSM7 ( -386 to +628), or LSM8 (-369 to +569). The LSM2, LSM3, LSM4, LSM5 and LSM8 genes were also introduced into a high-copy pRS425 (LEU2 2 $\mu$ ) plasmid. Missense mutations were introduced in the LSM2, LSM3, LSM4, LSM5 and LSM8 genes by two-stage PCR overlap extension with mutagenic primers. PCR overlap extension was also used to generate the C-terminal deletion mutation in LSM4-CA92. Mutated LSM genes were introduced into the pRS413- and pRS415-based expression plasmids. We also generated ten pRS316-LSM/LSM plasmids (URA3 CEN) carrying pairwise combinations of LSM2, LSM3, LSM4, LSM5, and LSM8, as well as a pRS415-LSM2/LSM3 plasmid (LEU2 CEN) for coexpression of LSM2 and LSM3.

\section{$U 6$ and PRP24 expression plasmids}

PCR amplification and standard cloning procedures were used to generate plasmids for overexpression of U6 snRNA and PRP24.

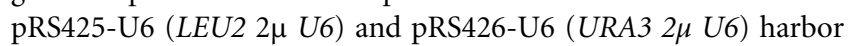
a 1.12-kb DNA segment spanning the genomic snR6 locus $(-540$ to +580). In pRS425-TPI1-PRP24 (LEU2 $2 \mu$ PRP24) and pRS316TPI1-PRP24 (URA3 CEN PRP24), the expression of PRP24 is under the transcriptional control of the TPI1 promoter.

\section{Yeast strains and tests of function in vivo}

All strains are haploid progeny of BY4743, a derivative of S288C. To develop plasmid shuffle assays to test the effects of $L S M$ mutations, we generated $l s m \Delta$ p [URA3 CEN LSM] haploids by sporulation and dissection of heterozygous $L S M / \operatorname{lsm} \Delta:: k a n M X$ diploids (Dharmacon) that had been transfected with pRS316-based LSM expression plasmids. We thereby obtained lsm2 $\mathrm{p}[U R A 3 \quad C E N$

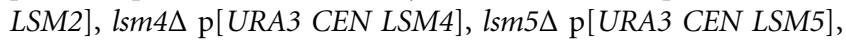
and $l \sin 8 \Delta \mathrm{p}$ [URA3 CEN LSM8] strains that were resistant to G418 $(150 \mathrm{mg} / \mathrm{L})$ and unable to grow on medium containing 0.75 $\mathrm{mg} / \mathrm{mL} 5$-fluoroorotic acid (FOA). $l s m 6 \Delta$ and $l s m 7 \Delta$ haploids did not rely on maintenance of the URA3 CEN plasmid and grew on FOA-containing medium, as expected (Mayes et al. 1999; SalgadoGarrido et al. 1999). We also generated a series of $l s m \Delta$ strains in which the kanMX marker was replaced by a natMX marker via transfection of a linear DNA segment containing the natMX cassette (Goldstein and McCusker 1999), followed by selection for nourseothricin-resistant transformants that were sensitive to G418. Using standard gene disruption methods, we replaced one allele of the LSM3 or PRP24 ORF with antibiotic-resistance cassettes in BY4743 diploids, transfected the heterozygous strains with URA3 CEN expression plasmids for LSM3 or PRP24 and subjected the $\mathrm{Ura}^{+}$diploids to sporulation and dissection to obtain $l \operatorname{sm} 3 \Delta:$ : hygMX, lsm3 $\Delta:: n a t M X$, and prp24 $\Delta:: h y g M X$ haploids that rely for growth on maintenance of the URA3 CEN LSM3 plasmid and the URA3 CEN PRP24 plasmid, respectively.
To assay the function of wild-type and mutated $L S M$ alleles, $1 \mathrm{sm} \Delta$ p [URA3 CEN LSM] cells were transfected with pRS413-based LSM expression plasmids. Individual $\mathrm{His}^{+}$transformants were selected, streaked on agar medium containing FOA, and incubated at $30^{\circ} \mathrm{C}$. Plasmid-borne $L S M$ alleles that failed to sustain formation of macroscopic colonies after $8 \mathrm{~d}$ were deemed lethal. Individual FOAresistant colonies with viable $L S M$ alleles were grown to mid-log phase in YPD broth and adjusted to the same $A_{600}$ values. Aliquots $(3 \mu \mathrm{L})$ of serial 10 -fold dilutions were spotted on YPD agar plates, which were then incubated at temperatures ranging from $18^{\circ} \mathrm{C}$ to $37^{\circ} \mathrm{C}$. Strains that grew similarly to wild-type at one or more temperatures tested, but formed small colonies at the others were scored as "sick." Strains were categorized as "very sick," if they grew poorly at all temperatures, forming pinpoint colonies at best. Strains scored as ts grew at low temperatures, but failed to form colonies at high temperatures. Strains scored as cs grew at high temperatures, but failed to form colonies at low temperatures.

\section{Tests of mutational synergy with other Lsm subunits}

Haploid strains in which pairs of $l s m \Delta$ alleles are complemented by the corresponding pRS316-LSM/LSM plasmids were generated by pairwise crossing of $l s m \Delta$ pRS316-LSM haploids of the opposite mating type. The heterozygous diploids were plated to FOA agar to select against the URA3 CEN LSM plasmids and subsequently transfected with the appropriate pRS316-LSM/LSM plasmids. $\mathrm{Ura}^{+}$ transformants were selected and subjected to sporulation and dissection. We thereby generated strains $l s m 2 \Delta:: k a n M X l s m 3 \Delta:: n a t M X$

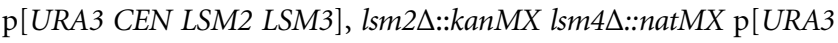
CEN LSM2 LSM4], lsm2 $:: k a n M X ~ l s m 5 \Delta:: n a t M X$ p[URA3 CEN

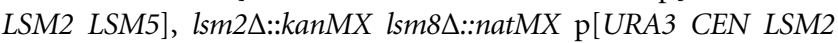

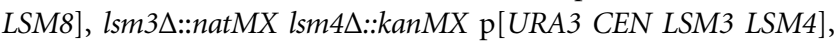

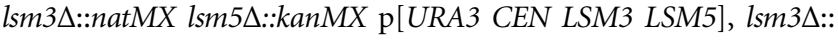

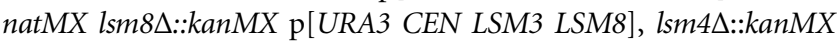

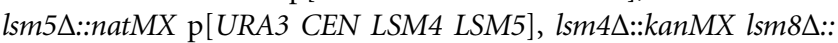
natMX p[URA3 CEN LSM4 LSM8], and lsm5 kanMX p[URA3 CEN LSM5 LSM8] that failed to grow on FOA medium unless they had been cotransfected with CEN HIS3 plus CEN LEU2 plasmids harboring the corresponding LSM genes. The function of mutated LSM alleles in various combinations was assessed by plasmid shuffle as described above. We also generated strain lsm6 $6:$ :natMX lsm7::kanMX p[URA3 CEN LSM6]. Viability of $l s m 6 \Delta$ $l s m 7 \Delta$ p [URA3 CEN LSM6] cells on FOA medium relies on prior transfection with a pRS415-based expression plasmid for either LSM6 or LSM7.

Haploid strains in which three $\operatorname{lsm} \Delta$ alleles are complemented by a pRS426-U6 plasmid were generated by crossing $l s m 2 \Delta:: k a n M X$

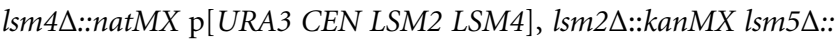
natMX p[URA3 CEN LSM2 LSM5], or lsm2 natMX p [URA3 CEN LSM2 LSM8] cells to lsm3A::hygMX p [URA3 CEN LSM3] haploids of the opposite mating type. G418- and hygromycin-resistant diploids were plated to FOA agar to select against the URA3 CEN LSM plasmids and subsequently transfected with plasmid pRS426-U6. $\mathrm{Ura}^{+}$transformants were selected and subjected to sporulation and dissection. We thereby generated

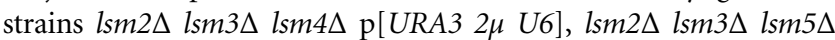
$\mathrm{p}[U R A 32 \mu U 6]$, and $l s m 2 \Delta l s m 3 \Delta l s m 8 \Delta \mathrm{p}[U R A 32 \mu U 6]$. The triple deletion strains failed to grow on FOA medium unless they had been cotransfected with a pRS415-LSM2/LSM3 plasmid and a 
pRS413-based expression plasmid for LSM4, LSM5 or LSM8, respectively.

\section{SUPPLEMENTAL MATERIAL}

Supplemental material is available for this article.

\section{ACKNOWLEDGMENTS}

This work was supported by National Institutes of Health (National Institute of General Medical Sciences) grants GM52470 (S.S. and B.S.) and GM102961 (B.S.).

Received February 13, 2018; accepted March 30, 2018.

\section{REFERENCES}

Agarwal R, Schwer B, Shuman S. 2016. Structure-function analysis and genetic interactions of the Luc7 subunit of the Saccharomyces cerevisiae U1 snRNP. RNA 22: 1302-1310.

Burke JE, Butcher SE, Brow DA. 2015. Spliceosome assembly in the absence of stable U4/U6 RNA pairing. RNA 21: 923-934.

Chan SP, Kao DI, Tsai WY, Cheng SC. 2003. The Prp19p-associated complex in spliceosome activation. Science 302: 279-282.

Didychuk AL, Montemayor EJ, Brow DA, Butcher SE. 2016. Structural requirements for protein-catalyzed annealing of U4 and U6 RNAs during di-snRNP assembly. Nucleic Acids Res 44: 1398-1410.

Didychuk AL, Montemayor EJ, Carrocci TJ, DeLaitsch AT, Lucarelli SE, Westler WM, Brow DA, Hoskins AA, Butcher SE. 2017. Usb1 controls U6 snRNP assembly through evolutionarily divergent cyclic phosphodiesterase activities. Nat Commun 8: 497.

Didychuk AL, Butcher SE, Brow DA. 2018. The life of U6 small nuclear RNA, from cradle to grave. RNA 24: 437-460.

Goldstein AL, McCusker JH. 1999. Three new dominant drug resistance cassettes for gene disruption in Saccharomyces cerevisiae. Yeast 15: 1541-1543.

Hossain MA, Claggett JM, Nguyen T, Johnson TL. 2009. The cap binding complex influences $\mathrm{H} 2 \mathrm{~B}$ ubiquitination by facilitating splicing of the SUS1 pre-mRNA. RNA 15: 1515-1527.

Jacewicz A, Chico L, Smith P, Schwer B, Shuman S. 2015. Structural basis for recognition of intron branchpoint RNA by yeast Msl5 and selective effects of interfacial mutations on splicing of yeast pre-mRNAs. RNA 21: 401-414.

Kambach C, Walke S, Young R, Avis JM, de la Fortelle E, Raker VA, Lührmann R, Li J, Nagai K. 1999. Crystal structures of two Sm protein complexes and their implications for the assembly of the spliceosomal snRNPs. Cell 96: 375-387.

Kondo Y, Oubridge C, van Roon AM, Nagai K. 2015. Crystal structure of human U1 snRNP, a small nuclear ribonucleoprotein particle, reveals the mechanism of $5^{\prime}$ splice site recognition. eLife 4: e04986.

Li Z, Brow DA. 1993. A rapid assay for quantitative detection of specific RNAs. Nucleic Acids Res 21: 4645-4646.

Li J, Leung AK, Kondo Y, Oubridge C, Nagai K. 2016. Re-refinement of the spliceosomal U4 snRNP core-domain structure. Acta Crystallogr D Struct Biol 72: 131-146.

Lund E, Dahlberg JE. 1992. Cyclic 2',3'-phosphates and nontemplated nucleotides at the $3^{\prime}$ end of spliceosomal U6 small nuclear RNA's. Science 255: 327-330.
Mayes AE, Verdone L, Legrain P, Beggs JD. 1999. Characterization of Sm-like proteins in yeast and their association with U6 snRNA. EMBO J 18: 4321-4331.

Montemayor EJ, Curran EC, Liao HH, Andrews KL, Treba CN, Butcher SE, Brow DA. 2014. Core structure of the U6 small nuclear ribonucleoprotein at 1.7- $\AA$ resolution. Nat Struct Mol Biol 21: $544-551$.

Montemayor EJ, Didychuk AL, Liao H, Hu P, Brow DA, Butcher SE. 2017. Structure and conformational plasticity of the U6 small nuclear ribonucleoprotein core. Acta Crystallogr D Struct Biol 73: 1-8.

Mroczek S, Krwawicz J, Kutner J, Lazniewski M, Kuciński I, Ginalski K, Dziembowski A. 2012. C16orf57, a gene mutated in poikiloderma with neutropenia, encodes a putative phosphodiesterase responsible for the U6 snRNA 3' end modification. Genes Dev 26: 1911-1925.

Nguyen THD, Galej WP, Bai XC, Oubridge C, Newman AJ, Scheres SHW, Nagai K. 2016. Cryo-EM structure of the yeast U4/U6.U5 tri-snRNP at $3.7 \AA$ resolution. Nature 530: 298-302.

Pannone BK, Kim SD, Noe DA, Wolin SL. 2001. Multiple functional interactions between components of the Lsm2-Lsm8 complex, U6 snRNA, and the yeast La protein. Genetics 158: 187-196.

Plaschka C, Lin PC, Nagai K. 2017. Structure of a pre-catalytic spliceosome. Nature 546: 617-621.

Qiu ZR, Chico L, Chang J, Shuman S, Schwer B. 2012. Genetic interactions of hypomorphic mutations in the $\mathrm{m}^{7} \mathrm{G}$ cap-binding pocket of yeast nuclear cap binding complex: an essential role for $\mathrm{Cbc} 2$ in meiosis via splicing of MER3 pre-mRNA. RNA 18: 1996-2011.

Rader SD, Guthrie C. 2002. A conserved Lsm-interaction motif in Prp24 required for efficient U4/U6 di-snRNP formation. RNA 8: 1378-1392.

Raghunathan PL, Guthrie C. 1998. A spliceosomal recycling factor that reanneals U4 and U6 small nuclear ribonucleoprotein particles. Science 279: 857-860.

Salgado-Garrido K, Bragado-Nilsson E, Kandels-Lewis S, Séraphin B. 1999. Sm and Sm-like proteins assemble in two related complexes of deep evolutionary origin. EMBO J 18: 3451-3462.

Schwer B, Shuman S. 2015. Structure-function analysis and genetic interactions of the Yhc1, SmD3, SmB, and Snp1 subunits of yeast U1 snRNP and genetic interactions of SmD3 with U2 snRNP subunit Lea1. RNA 21: 1173-1186.

Schwer B, Kruchten J, Shuman S. 2016. Structure-function analysis and genetic interactions of the $\mathrm{SmG}, \mathrm{SmE}$, and $\mathrm{SmF}$ subunits of the yeast Sm protein ring. RNA 22: 1320-1328.

Schwer B, Roth AJ, Shuman S. 2017. Will the circle be unbroken: specific mutations in the yeast $\mathrm{Sm}$ protein ring expose a requirement for assembly factor Brr1, a homolog of Gemin2. RNA 23: 420-430.

Sharif H, Conti E. 2013. Architecture of the Lsm1-7-Pat1 complex: a conserved assembly in eukaryotic mRNA turnover. Cell Rep 5: 283-291.

Tharun S, He W, Mayes AE, Lennertz P, Beggs JD, Parker R. 2000. Yeast Sm-like proteins function in mRNA decapping and decay. Nature 404: 515-518.

Wu D, Jiang S, Bowler MW, Song H. 2012. Crystal structures of Lsm3, Lsm4 and Lsm5/6/7 from Schizosaccharomyces pombe. PLoS One 7: e36768.

Zhou L, Hang J, Zhou Y, Wan R, Lu G, Yin P, Yan C, Shi Y. 2014a. Crystal structures of the Lsm complex bound to the $3^{\prime}$ end sequence of U6 small nuclear RNA. Nature 506: 116-120.

Zhou L, Zhou Y, Hang J, Wan R, Lu G, Yan C, Shi Y. 2014b. Crystal structure and biochemical analysis of the heptameric Lsm1-7 complex. Cell Res 24: 497-500. 

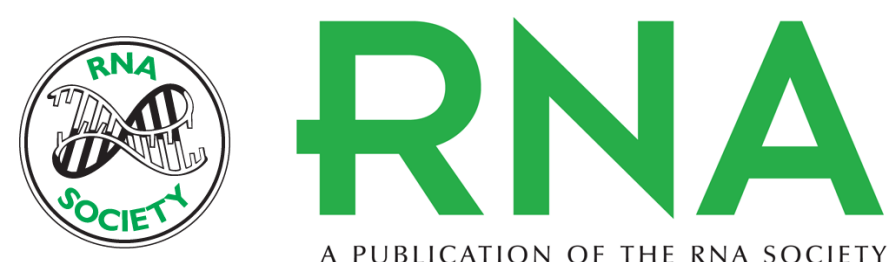

A PUBLICATION OF THE RNA SOCIETY

\section{Defining essential elements and genetic interactions of the yeast Lsm2 -8 ring and demonstration that essentiality of Lsm2-8 is bypassed via overexpression of U6 snRNA or the U6 snRNP subunit Prp24}

Allen J. Roth, Stewart Shuman and Beate Schwer

RNA 2018 24: 853-864 originally published online April 3, 2018

Access the most recent version at doi:10.1261/rna.066175.118

Supplemental Material

References

Creative

Commons

License

Email Alerting Service
http://rnajournal.cshlp.org/content/suppl/2018/04/03/rna.066175.118.DC1

This article cites 33 articles, 17 of which can be accessed free at: http://rnajournal.cshlp.org/content/24/6/853.full.html\#ref-list-1

This article is distributed exclusively by the RNA Society for the first 12 months after the full-issue publication date (see http://rnajournal.cshlp.org/site/misc/terms.xhtml). After 12 months, it is available under a Creative Commons License (Attribution-NonCommercial 4.0 International), as described at http://creativecommons.org/licenses/by-nc/4.0/.

Receive free email alerts when new articles cite this article - sign up in the box at the top right corner of the article or click here.

To subscribe to $R N A$ go to:

http://rnajournal.cshlp.org/subscriptions 